\title{
Therapeutic Management of Pulmonary Tuberculosis by Mannosylated Chitosan Ascorbate Microspheres: Preparation and Characterization
}

\author{
Archana Bagre, Narendra Kumar Lariya, Mohan Lal Kori \\ Vedica College of B. Pharmacy, RKDF University, Gandhinagar, Bhopal, Madhya Pradesh, India
}

\begin{abstract}
Objective: In this study, biodegradable Chitosan Ascorbate Microsphere (CAMs) and mannosylated chitosan ascorbate microsphere (m-CAMs) prepared for targeting towards alveolar macrophages to treatment of pulmonary tuberculosis.

Significance: Ascorbic acid is an antioxidant and reported killing effect on mycobacterium by induces fenton reaction. This study enlightens the possible benefits of adding antioxidant properties of ascorbic acid with chitosan microsphere to an anti-tuberculosis regimen and mannosylation of microsphere significantly induce the targetability of antitubercular drug to alveolar macrophages.

Methods: CAMs prepared by firstly salification of chitosan by ascorbic acid then ionic gelation with STPP and m-CAMs prepared by incubation method and purified for further studies. The physicochemical, in vitro and in vivo characterizations of both formulations were carried out.

Results: The size of microspheres (both CAMs and m-CAMs) were found to be in range of 3.40-4.81 $\mu \mathrm{m}$. Evident changes were observed in crystallinity and structure of both carrier systems and depicted by Fourier transform infrared (FTIR), Differential scanning calorimetry (DSC) and X-ray diffraction (XRD) studies. In vitro lung deposition study of microspheres showed favourable aerodynamic properties for deep lung delivery (MMAD 2.0- $3.8 \mu \mathrm{m}$ ) and, thus, show potential for an application as inhalable tuberculosis therapy. The drug release showed the biphasic pattern of release, i.e., initial burst (30-45\% up to $8 \mathrm{~h}$ ) followed by a slower sustained release pattern (more than $80 \%$ up to $72 \mathrm{~h}$ ) in both simulated lung fluids. Optimized formulations exhibited lower cytotoxicity and bio distribution studies demonstrated the efficiency of $\mathrm{m}$ CAMs for spatial delivery of INH to alveolar tissues. CAMs and m-CAMs evidenced minor cytotoxicity on lung epithelial cells (A549 cell lines). Conclusion: m-CAMs thus has a promising potential to be explore as an effective carrier system for delivery of antitubercular drugs regimen.
\end{abstract}

Key words: Targetability, alveolar macrophage, lung cancer A549 cells

Article Info: Received 20 March 2019; $\quad$ Review Completed 21 April 2019; $\quad$ Accepted 22 April 2019; Available online 15 May 2019

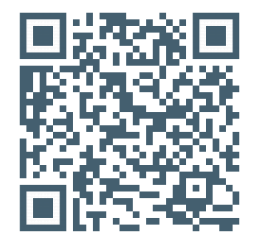

\section{Cite this article as:}

Bagre A, Lariya NK, Kori ML, Therapeutic Management of Pulmonary Tuberculosis by Mannosylated Chitosan Ascorbate Microspheres: Preparation and Characterization, Journal of Drug Delivery and Therapeutics. 2019; 9(3):13-25 http://dx.doi.org/10.22270/jddt.v9i3.2805

Dr. Mohan Lal Kori, Vedica College of B. Pharmacy, RKDF University, Airport Bypass Road, Gandhinagar, Bhopal, Madhya Pradesh, India

\section{INTRODUCTION}

Worldwide, Tuberculosis (TB) is one of the top 10 causes of death and the leading cause from a single infectious agent (above HIV/AIDS) ${ }^{1}$. The World Health Organization has set a deadline to end the TB epidemic by 2035 , which includes a 90-95\% reduction in TB incidence and in the number of TBrelated deaths 2, 3. The causative agent Mycobacterium tuberculosis (MTB), an intracellular parasitic pathogen resides in alveolar Macrophage (AM) that mainly affects the respiratory tract.

The current treatment regimen for TB consists of administering the drugs via oral or parenteral routes which remain challenging for clinicians because of high systemic delivery of single or multiple drug associated with various problems i.e. patient incompliance, toxic effects and development of resistance due to high systemic exposure 4, 5 . Due to poor pulmonary tissue diffusion of the administered drugs, the drug concentration achieved in the lungs is in the sub-therapeutic range, when given by these conventional routes. Thus, the situation has come to a point where the development of novel intervention strategies is urgently needed.

A well-explored way to deliver anti-TB drugs is via the pulmonary route by which high concentrations can be achieved in the lungs which would be coupled with low systemic bio-distribution and toxicity. The ways of direct pulmonary administration of drugs include nebulization of drug solutions or particulate formulations including nanoparticles, liposomes and microparticles.

In this regard, inhalable therapy has great potential, allowing the direct administration of drugs to the infection site. This approach would potentially enable reducing the dosing frequency and shorten the treatment duration, thereby avoiding severe systemic side effects and improving patient compliance. Implementing this therapeutic strategy requires the design of antitubercular inhalable formulations with 
suitable aerodynamic properties to reach the alveoli, where the alveolar macrophages infected with M. tuberculosis are located.

Substantial research has been done to develop alveolar macrophage targeting for pulmonary delivery wherein the drugs are entrapped in polymers, copolymers and lipids. Such formulations include microparticles 6-8, nanoparticles 5 , ${ }^{9}$, solid lipid nanoparticles ${ }^{2}$ etc.

Chitosan is deacetylated derivative of chitin, is widely distributed in nature and has been widely used as a drug carrier offering advantages of mucoadhesivity, good biocompatibility, non-immunogenicity, and non-toxicity 10,11 . Over the years, micro and nano-particulate carrier systems composed of chitosan polymer have widely been studied for the delivery of drugs and bio-macromolecules. It displays unique property of binding to the cell membrane which is manifested as enhancement in its cellular uptake and transfection efficiency.

Ascorbic acid is a well-known antioxidant present in cells and plasma of humans. Its beneficial effect and antioxidant properties have been widely studied. But due to unstability, get oxidised to dehydroascorbic acid in light air and temperature. To increase the stability of Ascorbic acid various derivatives have been synthesized, including the metal salts ( $\mathrm{Na}, \mathrm{Ca}$ salts), ethers, esters and the polysaccharide derivatives 12 . Here chitosan properties combined with ascorbic acid by formation of chitosan ascorbate, a soluble ketimine formed due to salification of chitosan has shown increased stability, antioxidant properties, permeability and adhesiveness. Applications of chitosan properties with ascorbic acid applied previously in various field wound healing ${ }^{13}$, vaginal delivery of peptides 14.

Interestingly, one finding has demonstrated that ascorbic acid sterilized he culture of drug susceptible and drug resistant mycobacterium tuberculosis the generation of highly reactive hydroxyl radicals via the Fenton reaction 15 , Recently, it has been investigated that ascorbic acid had no activity by itself in $M$. tuberculosis-infected mice, the combination of it with the first line TB drugs reduced the bacterial burden in the lungs of M. tuberculosis-infected mice faster than drug alone 16 .

To the best of our knowledge, we believe so far there are no reports on the synthesis of chitosan ascorbate microspheres for pulmonary delivery of antitubercular drugs. In view of its unique properties reported earlier with little knowledge about the nano form of this compounds characteristics ${ }^{17}$, the present study aims to investigate the microspherical formation, its physiochemical properties, antioxidant efficacy, in-vitro drug release and lung deposition study, cytotoxicity on A549 cell line. We hypothesize that this proposed approach would surmount precise toxicity limitations and be a utile choice of carrier system based drug delivery with therapeutic properties.

\section{MATERIALS AND METHODS}

Isoniazid (purity>99\%) was received as a gift sample by Lupin Ltd, Aurangabad (Maharashtra India). Chitosan have degree of deacetylation (80.0-95\%), sodium tripolyphosphate (STPP), L-Ascorbic acid (99\%), FITC Dye were purchased from Sigma-Aldrich, India. Methanol and Acetonitrile (HPLC grades) was purchased from $\mathrm{CDH}$ chemicals. DMEM Medium with High Glucose and Fetal Bovine Serum (FBS), Penicillin-Streptomycin Solution, FITC and MTT were purchased from Sigma Co., Ltd. All the chemicals and ingredients utilized for studies were of AR grade. Double distilled water was utilized throughout the study.

\section{Preparation of Mannosylated Chitosan Ascorbate Microsphere (m-CAMs):}

Mannosylated Chitosan Ascorbate Microspheres (m-CAMs) were prepared by a two-step process involving (i) in-situ synthesis of Chitosan Ascorbate Microsphere (CAMs) and (ii) mannosylation of above prepared CAMs (m-CAMs).

CAMs were synthesized by modified ionotropic gelation. 1.5 $\%(\mathrm{w} / \mathrm{v})$ low molecular weight chitosan powder was added to $1.0 \mathrm{M}$ ascorbic acid solution and stirred continuously until a clear solution obtained. The solution was allowed to stand for $3 \mathrm{~h}$. Then addition of $5 \%(\mathrm{w} / \mathrm{v})$ STPP solution at 8 $\mathrm{ml} / \mathrm{min}$ flow rate and $800 \mathrm{rpm}$ (Multistage magnetic stirrer, Velp, Italy) for $30 \mathrm{~min}$. The dropping rate and falling distance of STPP solution were kept constant. Then spontaneously formed microsphere suspension was kept overnight then centrifuge at $5000 \mathrm{rpm}$ for $5 \mathrm{~min}$. The microspheres were washed two times with distilled water, laid out on aluminium trays, and dried until weight remains constant. INH loaded Chitosan Ascorbate microsphere (INH-CAMs) were prepared using the procedure just described, except INH (100mg) dissolved initially in chitosan solution. Optimization studies performed to achieve optimum size of formulation for pulmonary delivery of INH [Table 1].

Table 1: Optimization of formulation variable:

\begin{tabular}{|c|c|c|c|c|l|}
\hline Formulation & Concentration & $\begin{array}{c}\text { Particle size } \\
(\mu \mathrm{m})\end{array}$ & Zeta potential & PDI & $\begin{array}{l}\text { Entrapment } \\
\text { Efficiency of INH }\end{array}$ \\
\hline Ascorbic Acid Concentration $(\mathrm{M})$ & 0.5 & $4.01 \pm 0.25$ & $20.3 \pm 1.1$ & $0.30 \pm 0.04$ & $58.14 \pm 0.12$ \\
\hline & $\mathbf{1 . 0}$ & $\mathbf{3 . 2 5} \pm \mathbf{0 . 1 4}$ & $\mathbf{2 8 . 1} \pm \mathbf{1 . 4}$ & $\mathbf{0 . 5 3} \pm \mathbf{0 . 0 7}$ & $\mathbf{6 1 . 4 2} \pm \mathbf{0 . 2 0}$ \\
\hline & 1.5 & $2.14 \pm 0.11$ & $27.4 \pm 2.1$ & $0.37 \pm 0.03$ & $62.90 \pm 0.21$ \\
\hline Chitosan concentration $(\% \mathrm{w} / \mathrm{v})$ & 0.5 & $1.98 \pm 0.78$ & $24.2 \pm 2.2$ & $0.67 \pm 0.06$ & $60.81 \pm 0.14$ \\
\hline & $\mathbf{1 . 5}$ & $\mathbf{3 . 5 8} \pm \mathbf{0 . 3 4}$ & $\mathbf{3 6 . 2} \pm \mathbf{1 . 2}$ & $\mathbf{0 . 7 5} \pm \mathbf{0 . 0 3}$ & $\mathbf{6 3 . 3 4 \pm 0 . 9 1}$ \\
\hline & 2.5 & $5.66 \pm 0.54$ & $38.5 \pm 3.1$ & $0.71 \pm 0.18$ & $59.25 \pm 0.40$ \\
\hline STPP concentration $(\mathrm{w} / \mathrm{v})$ & 1 & $2.10 \pm 0.40$ & $36.2 \pm 2.6$ & $0.52 \pm 0.16$ & $59.14 \pm 0.12$ \\
\hline & $\mathbf{5}$ & $\mathbf{3 . 1 0} \pm \mathbf{0 . 2 0}$ & $\mathbf{3 9 . 4 \pm 2 . 9}$ & $\mathbf{0 . 4 1} \pm \mathbf{0 . 0 8}$ & $\mathbf{6 2 . 4 4} \pm \mathbf{0 . 2 2}$ \\
\hline & 10 & $4.91 \pm 0.51$ & $22.9 \pm 1.2$ & $1.02 \pm 0.60$ & $56.21 \pm 0.32$ \\
\hline
\end{tabular}

Note: All values are expressed as mean \pm S.D. $(n=3)$ 
Table 2: Optimization of incubation time during mannosylation:

\begin{tabular}{llll}
\hline Formulation & Incubation Time & Average size & Zeta Potential \\
\hline Optimization of incubation time & 12 & $5.81 \pm 1.44$ & $-21.1 \pm 1.22$ \\
& $\mathbf{2 4}$ & $\mathbf{4 . 1 0 \pm \mathbf { 1 . 5 8 }}$ & $\mathbf{- 1 7 . 5 4 \pm 0 . 6 8}$ \\
& 48 & $6.47 \pm 2.14$ & $-26.87 \pm 0.41$ \\
\hline
\end{tabular}

Mannosylation was carried out by adopting the method describe 18, 19 with certain modification. The coupling of mannose to the amine group of chitosan was carried out in two steps. In first step, coupling reaction done initially where D-mannose $(10 \mu \mathrm{m})$ was dissolved in $0.1 \mathrm{M}$ sodium acetate buffer at $\mathrm{pH} 4$ and $60^{\circ} \mathrm{C}$ for $2 \mathrm{hr}$ resulting in the ring opening of mannose molecule. In second step, this solution was mixed thoroughly with chitosan microsphere synthesized earlier and incubated for $24 \mathrm{hr}$ at room temperature. The aldehyde group of ring opened mannose reacts with amine group of chitosan, yielding mannosylated chitosan and the resulting solution centrifuged at 5000rpm and washed thoroughly with distilled water.

Purification of m-CAMs: Formulation were purified by dialyzing against double distilled water in a dialysis tube ( $>900 \mathrm{KDa}$ MWCO) for $24 \mathrm{hr}$ to remove any unreacted drug and polymer.

\section{Physico-chemical characterization of carrier system:}

Particle size Analysis and morphological characteristics: Particle size was determined by digital photographic microscope and Malvern ZetaSizer (Mastersizer X, Malvern Instruments Ltd., UK). For determination of particle size, the microspheres were suspended in methanol containing $0.1 \%$ Tween 80 to prevent aggregation, and the mean particle size and polydispersity index were determined. For determination of zeta potential, the microspheres were suspended in de-ionized water and placed in disposable polystyrene electrophoretic cells. The total zeta runs were 100 and the count rate was 250 particles/sec. The experiments were performed in triplicate.

The surface characteristics were studied by scanning electron microscope (Model JSM-6390A, JEOL, Japan) from $5 \mathrm{X}$ to $300000 \mathrm{X}$ magnifications at the MSME Department, MANIT, Bhopal India. The powder sample was sprinkled onto the carbon tape affixed on aluminium stubs. The aluminium stubs were placed in the vacuum chamber and observed for morphological characterization.

Powder X-ray Diffraction (PXRD) Studies: PXRD were determined for drug and drug loaded carrier systems CAMs and m-CAMs. Samples were exposed to a monochromatic nickel-filtered copper radiation $(40 \mathrm{kV}, 30 \mathrm{~mA})$ in a wideangle X-ray diffractometer (XPERT-PRO system) with $2 \theta$ angle.

FTIR Study: Samples were prepared in $\mathrm{KBr}$ disc $(4 \mathrm{mg}$ sample/200 mg KBr) using a hydrostatic press at a force of 40 psi for $4 \mathrm{~min}$. Each sample was scanned thrice between 4000 and $400 \mathrm{~cm}^{-1}$ at a resolution of $4 \mathrm{~cm}^{-1}$ and averaged for that sample and there were three $(n=3)$ different samples scanned.

Differential scanning calorimetry (DSC): DSC was performed for chitosan, ascorbic acid and CAMs using a PyrisTM Diamond DSC (PerkinElmer). Accurately weighted samples $(5 \pm 0.1 \mathrm{mg})$ were used for the analysis, and it was sealed in aluminum pans. They were scanned from $50^{\circ} \mathrm{C}$ to $350 \stackrel{\circ}{ } \mathrm{C}$ at $10 \stackrel{\circ}{\circ} \mathrm{C} / \mathrm{min}$.

Antioxidant activity assay: Antioxidant activity assay performed for chitosan ascorbate microsphere by following method 20, 21. Different concentrations of testing samples and
$2 \mathrm{~mL}$ of DPPH ethanol solution $(180 \mu \mathrm{mol} / \mathrm{L})$ were incubated for $30 \mathrm{~min}$ at room temperature. Then, the absorbance of the remained DPPH radical was measured at $517 \mathrm{~nm}$ against a blank. Three replicates for each sample were tested and the DPPH-radical scavenging effect was calculated according to the following equation:

Scavenging effect $(\%)=\frac{1-\text { Asample } 517 \mathrm{~nm}-\text { Acontrol } 517 \mathrm{~nm}}{\text { Ablank } 517 \mathrm{~nm}} \times 100$

Where Asample $517 \mathrm{~nm}$ is the absorbance of the samples, Acontrol $517 \mathrm{~nm}$ is the absorbance of the control (DPPH was substituted with ethanol), and Ablank $517 \mathrm{~nm}$ is the absorbance of the blank (samples were substituted with distilled water). Pure ascorbic acid solution was used as a positive control.

In-vitro lung deposition study: In-vitro lung deposition pattern of formulation determined by an Andersen Cascade Impactor (ACI) (Thermofisher Scientific, U.K.) by calculated parametrs i.e. percent emitted dose (\% ED), mass median aerodynamic diameter (MMAD) and fine particle fraction (FPF) of various formulations. Optimized formulations having higher drug loading were selected for this study and accurately weighted amount was mixed with micronized lactose at a 1:3 $(\mathrm{w} / \mathrm{w})$ ratio and dosed in an eight-stage nonviable Anderson cascade impactor. After the completion of dosing) \% ED, MMAD and FPF were calculated from the deposition data using the MMAD calculator for Anderson apparatus using a flow rate of $28.3 \mathrm{~L} / \mathrm{min}$. The experiment was performed in triplicate.

In-vitro drug release study: Release study of INH were independently conducted in two simulated lungs fluids; Gamble's Solution (pH 7.4) and Alveolar Lung Fluid (ALF pH 4.5) 22, 23. A USP Type II tablet dissolution test apparatus (Electrolab, Mumbai, INDIA) was used for in-vitro drug release. The stirring speed was kept 150rpm. A dialysis membrane (Himedia, molecular weight cut-off $>900 \mathrm{kDa}$ ) was cut into equal pieces of about $6 \mathrm{cmX} 2.5 \mathrm{~cm}$ and pretreated. Equivalent to $5 \mathrm{mg}$ each of INH loaded CAMs and $\mathrm{m}$ CAMs were dispersed in $1 \mathrm{ml}$ of PBS pH 7.4 and filled in the pre-treated dialysis membrane and sealed with clips. The pouch thus formed was attached to the paddles of the apparatus using rubber bands wound over the clips. Ninehundred millilitres of Gamble's solution $\mathrm{pH} 7.4$ and Alveolar Lung Fluid pH 4.5 (ALF) were used for the study. Samples of $5 \mathrm{ml}$ were drawn and $5 \mathrm{ml}$ fresh medium was replaced at each time interval $0.5,1,2,4,6,8,16,24,48,72 \mathrm{hr} 24$. The drug was estimated at $262 \mathrm{~nm}$ using UV-Visible spectrophotometer (Model 1800 UV-Visible spectrophotometer, Shimadzu, Japan). All the samples were tested in triplicates.

\section{In-vitro Cell proliferation Assay:}

\section{Cell lines and medium:}

Human non-small cell lung cancer, A549 cell line was initially procured from National Center for Cell Sciences (NCCS), Pune, India and then cultured in $95 \%$ air and 5\% $\mathrm{CO}_{2}$ at $37{ }^{\circ} \mathrm{C}$ using DMEM (Dulbecco's Modified Eagle's Medium) supplemented with Fetal Bovine serum (FBS 10\% $\mathrm{v} / \mathrm{v})$ and penicillin $(1 \% \mathrm{v} / \mathrm{v})$. All experiments were performed with asynchronous cell populations in exponential growth phase ( $24 \mathrm{~h}$ after plating) 25 . 
Cytotoxicity was determined by standard colorimetry based, MTT (3- $[4,5$ dimethylthiazol-2-yl]-2, 5 diphenyltetra zoliumbromide) assay 26 . In brief, $5 \times 10^{4}$ A549 cells were seeded in 96 well plates allowed to grow for $24 \mathrm{~h}$. A549 cells were then exposed continuously to pure INH solution (PBS, $\mathrm{pH}$ 7.4), CAMs suspension (PBS, pH 7.4), m-CAMs suspension (PBS, pH 7.4), INH loaded CAMs and INH loaded m-CAMs at a concentration equivalent to $20-100 \mu \mathrm{g} / \mathrm{mL}$. At $24 \mathrm{~h}$ treatment period with formulations A549 cells were incubated with MTT $(0.5 \mathrm{mg} / \mathrm{mL})$ for $4 \mathrm{~h}$ at $37 \circ \mathrm{C}$. The cells were lysed and the formazan crystals were dissolved by using $100 \mu \mathrm{l}$ of DMSO. The absorbance was read at $570 \mathrm{~nm}$ by using $630 \mathrm{~nm}$ as reference wavelength in ELISA (Enzyme linked immunosorbent assay)

$$
\text { Cell viability }(\%)=\frac{\text { A579experiment }- \text { A570blank }}{\text { A570control }- \text { A570blank }} \times 100
$$

\section{Pharmacokinetic study and biodistribution studies:}

Female BALB/c mice (20-30 g) were used to carried out the pharmacokinetic and organ biodistribution studies in accordance with the protocol approved by the Institutional Animal Ethics Committee, under the guidelines compiled by CPCSEA (Committee for the purpose of control Supervision of Experiments on Animal), Ministry of Culture, Government of India and the Local Institutional Animal Ethics Committee has approved all the study protocols vide approval no. IAEC/VCP/2018/001/2.

The drug distribution to various organs/tissues after intratracheal administration of microspheric formulations by aerosolization was performed using a MicroSprayerTM aerosoliser (IA-1C; Penn-Century, Philadelphia, PA, USA), attached to a high-pressure syringe (FMJ- 250; PennCentury). This device is an aerosol generator consisting of a sub-miniaturized atomizer located in the tip of a 1.25' stainless steel tube, which is attached to a hand operated, high-pressure syringe. Animals were divided into four groups (Table 5), each containing six animals $(n=6)$. Group 1 animals keep as a controlled and animals of group 2 were administered with $5 \mathrm{mg}$ INH in $500 \mu \mathrm{l}$ sterilized phosphate buffer saline through intra-trachea insillation. Similarly, group II and III received both formulations CAMs and mCAMs respectively, equivalent to $5 \mathrm{mg}$ drug, dispersed in $500 \mu \mathrm{l}$ PBS. Following the drug administration, blood was collected after 1, 2, 4, 8, 12 and $24 \mathrm{hr}$ through retro orbital plexus. Collected blood sample $0.5 \mathrm{ml}$ were centrifuge at $1000 \mathrm{rpm}$ for $20 \mathrm{~min}$; plasma was separated and filtered through membrane filter $0.45 \mu \mathrm{m}$.

Table 5: Selected groups for pharmacokinetic study:

\begin{tabular}{ll}
\hline Formulation & Formulations \\
\hline Group 1 & Controlled \\
\hline Group 2 & Free INH drug solution \\
Group 3 & INH loaded CAMs \\
Group 4 & INH loaded m-CAMs \\
\hline
\end{tabular}

Drug estimation in plasma was done using a developed highperformance liquid chromatography (HPLC) technique 27 and calibration curve was obtained by analyzing pooled blank plasma spiked with known amount of drug. The plasma concentration versus time data, obtained after intratracheal instillation of free drugs and different formulations were analyzed. The various pharmacokinetic parameters such as peak plasma concentration (Cmax), time taken to reach Cmax (Tmax), and area-under-the plasma drug concentration over time curve were calculated on a Sigma Plot software (version 8.0, Sigma, St. Louis, MO).
At the same time, selected organs (lungs, liver, spleen, and kidney) were excised, isolated, dried, weighed, and stored at $-80^{\circ} \mathrm{C} 28$. In the bio-distribution study, the stored isolated organs were recovered from deep freezer and kept out-side for some time at room temperature. Each tissue weighed separately, minced into pieces, and homogenized by tissue homogenizer (WiseMix HG-15D, Dathan Scientific, New Delhi, India) in phosphate buffer. The homogenized tissues were deproteinized with acetonitrile, vortexed (SwirlexVortex Shaker, Tarson Make) for $5 \mathrm{~min}$, centrifuged at $5000 \mathrm{~g}$ for $10 \mathrm{~min}$ at $4-8{ }^{\circ} \mathrm{C}$, kept in dark for $30 \mathrm{~min}$ and filtered. Supernatant was filtered through a membrane filter and used for the analysis of INH upon suitable dilution with mobile phase by HPLC technique and compared with calibration graphs (obtained by analyzing pooled blank plasma spiked with known drug amounts) to obtain the plasma drug concentration versus time profile 29 .

\section{Stastical analysis:}

Results were reported as mean \pm Standard Deviation (SD) for the different parameters assessed. Student's $t$-tests and One-Way Analysis of Variance (ANOVA) were used to compare between the independent variables, for two groups and more than two sets of data, respectively. For this purpose, IBM Statistical Package for Social Sciences (IBM SPSS $®$ Statistics-version 21) was used, and the difference was considered statistically significant when the calculated $\mathrm{p}$-value was less than 0.05 .

\section{RESULT AND DISCUSSION}

\section{Preparation of carrier system:}

For preparation of chitosan ascorbate microsphere (CAMs) chitosan ascorbate solution were prepared by salification of chitosan in ascorbic acid then resulting solution formed in a stable condition. Solubilization of chitosan by ascorbic acid due to the reactive amino groups in chitosan chains can be protonated by ascorbic acid molecules and form a positively charged water-soluble solution (Fig 1) ${ }^{30}$. The amount of chitosan conjugated with ascorbic acid was determined using ninhydrin method as a reagent to react with primary and secondary amine group in the polymer with various concentrations 31,32 . The percent degree of substitution was determined by comparing the slope obtained from standard D-glucosamine and chitosan and shown in Fig.2.

Eventually, chitosan ascorbate microspheres (CAMs) were synthesized by modified ionic gelation method using STPP into an aqueous solution of chitosan ascorbate. Chitosan, a polycationic polysaccharide is insoluble in alkaline and neutral $\mathrm{pH}$, but in acidic condition, protonated amine group of chitosan interacts with phosphate ions provided by STPP ion, either by intermolecular or intramolecular linkage 33-35. Particle size of microspheres formed majorly depends on the ascorbic acid concentration and degree of deacetylation. Chitosan with higher degree of deacetylation makes it susceptible to provides more number of effective binding sites for the ionic interaction with ample positive charge due to amino groups that protonated in the acidic environment 36. Whereas the increment in the concentration of ascorbic acid in which chitosan was dissolved also enhancing the ability of chitosan to form linkage with STPP anion hence microspheres decrease in particle size (Table 1). During optimizing the formulation, as we increased concentration of chitosan, the zeta potential increased due to the increase in the positive charge of the chitosan molecules. Higher chitosan concentration caused more unneutralized $-\mathrm{NH}_{3}{ }^{+}$on the microspheres surface, which led to a strong electrostatic repulsion between particles 37. This confirms that the formation of microspheres greatly depends on the 
concentration of free amine groups which increase the surface charge and zeta potential of the microspheres. In addition, when increasing the concentration of chitosan, the particle size increased in a linear manner with a correlation coefficient. The same result was obtained by several authors 38.

Increasing the concentration of STPP, reduced the zeta potential of micropsheres because at higher concentration, STPP brings more negatively charged phosphate ions which react with chitosan amino groups. Therefore, the positive surface charge of the microspheres decreases. In addition, the microspheres size increased when increasing STPP concentration. At low STPP concentrations (1\%), the amount of TPP was not enough to fully crosslink chitosan chains, and the preparations remained transparent. Further increase in TPP concentration (5\%) led to an increase in particle size and to a slightly opaque solution. At higher TPP concentration (10\%), very large and polydispersed particles were obtained. The same result was reported already ${ }^{39}$ who observed physical states of chitosan-TPP microspheres being either suspension (below a certain TPP concentration which depends on chitosan concentration) or precipitation (above a certain TPP concentration) in the range of TPP concentrations tested. However, optimized particle size was found to be increased to $4.10 \pm 1.58 \mu \mathrm{m}$ upon mannosylation. The increase in particle size after conjugation with mannose and zeta potential turned invert (Table. 2) can be due to the surface anchoring of mannose moieties to the amine groups present on the surface of CAMs ${ }^{19}$.

Table 3: Characteristic peaks of chitosan in IR spectrum

\begin{tabular}{|c|c|}
\hline Stretching/Bending vibration frequencies $\left(\mathrm{cm}^{-1}\right)$ & Functional Group and inference \\
\hline \multicolumn{2}{|c|}{ Characteristic peaks of chitosan in IR spectrum } \\
\hline 3417.5 & $\begin{array}{l}\text { Overlapping stretch vibrations of }-\mathrm{NH}_{2} \text { and }-\mathrm{OH} \\
\text { groups }\end{array}$ \\
\hline 1643 & Peak for $1^{\circ}$ amide- $\mathrm{I}$ and $-\mathrm{C}=\mathrm{O}$ \\
\hline 2923.6 & The aliphatic C-H stretching vibration \\
\hline 1383 & Weak deformation vibration of $\mathrm{C}-\mathrm{CH}_{3}$ \\
\hline \multicolumn{2}{|c|}{ Characteristic peaks of Ascorbic acid in IR spectrum } \\
\hline $3000-3500$ & Absorption band $\mathrm{OH}$ \\
\hline 1426 & $\mathrm{C}-\mathrm{O}$ \\
\hline 1736 & $\mathrm{C}=\mathrm{O}$ \\
\hline $3420,3359,3215$ & Four OH group \\
\hline \multicolumn{2}{|c|}{ Characteristic peak after interaction of chitosan and ascorbic acid during solubilisation } \\
\hline 3524 to 3214 & four $-\mathrm{OH}$ groups at $\mathrm{C}_{6}, \mathrm{C}_{3}, \mathrm{C}_{5}, \mathrm{C}_{2}$ \\
\hline 1754 & lactone $\mathrm{C}=\mathrm{O}$ forming intramolecular $\mathrm{H}$-bond \\
\hline 1673 & intermolecular H-bond \\
\hline 3524 to 3214 & four-OH groups at $\mathrm{C}_{6}, \mathrm{C}_{3}, \mathrm{C}_{5}, \mathrm{C}_{2}$ \\
\hline
\end{tabular}

\section{Characterization}

Ascorbic acid solubilizes the chitosan because chitosan contains amino groups which are protonatable in the acidic media, whereas ascorbic acid contains acidic hydroxyl functionality, thus allowing the formation of a complex through ionic interaction. Interaction between chitosan polymer and ascorbic acid during solublization was investigated by FTIR study (Fig. 2 and Table 3). FTIR spectra of chitosan shows in Fig. 3(a), a characteristic strong peak at $3417.5 \mathrm{~cm}^{-1}$ was attributed to overlapping stretch vibrations of $-\mathrm{NH}_{2}$ and $-\mathrm{OH}$ groups and the peak for amide $\mathrm{I}(\mathrm{C}=0)$ at $1643.7 \mathrm{~cm}^{-1}$ was seen. The aliphatic $\mathrm{C}-\mathrm{H}$ stretching vibration of the polymer backbone occurred at $2923.6 \mathrm{~cm}^{-1} 40$. The weak deformation vibration of $\mathrm{C}-\mathrm{CH}_{3}$ appeared at 1383.8 $\mathrm{cm}^{-1}$, indicating a higher degree of deacetylation of CS used in this experiment (Zhang et al. 2014). In FTIR ascorbic acid showed in Fig. 3(b) the four peaks from $3524 \mathrm{~cm}^{-1}$ to 3214 $\mathrm{cm}^{-1}$ were attributed to the four $-\mathrm{OH}$ groups at four carbon atoms. The stretch vibration of lactone $\mathrm{C}=\mathrm{O}$ forming intramolecular H-bond occurred at $1754.4 \mathrm{~cm}^{-1}$ and that of lactone $\mathrm{C}=\mathrm{O}$ forming intermolecular $\mathrm{H}$-bond occurred at $1673.8 \mathrm{~cm}^{-1}$ 41. This result suggested from Fig. 3(c) $\mathrm{NH}_{2}$ groups on the Chitosan chains were protonated by the $\mathrm{H}^{+}$supplied by Ascorbic acid. The decrease of peak at 3428.2 $\mathrm{cm}^{-1}$ in indicated the reduction of free $-\mathrm{NH}_{2}$ groups after solubilize the chitosan with ascorbic acid.

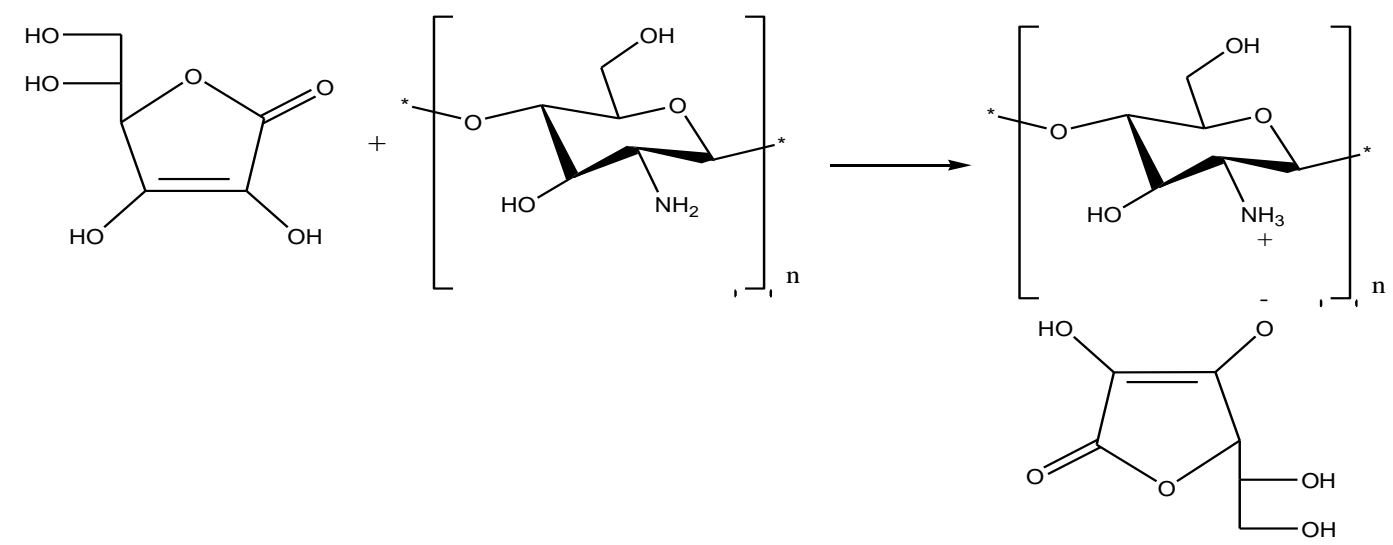

Figure 1: Interaction mechanism between A): Ascorbic acid B): chitosan polymer C): Final molecule Chitosan Ascorbate 


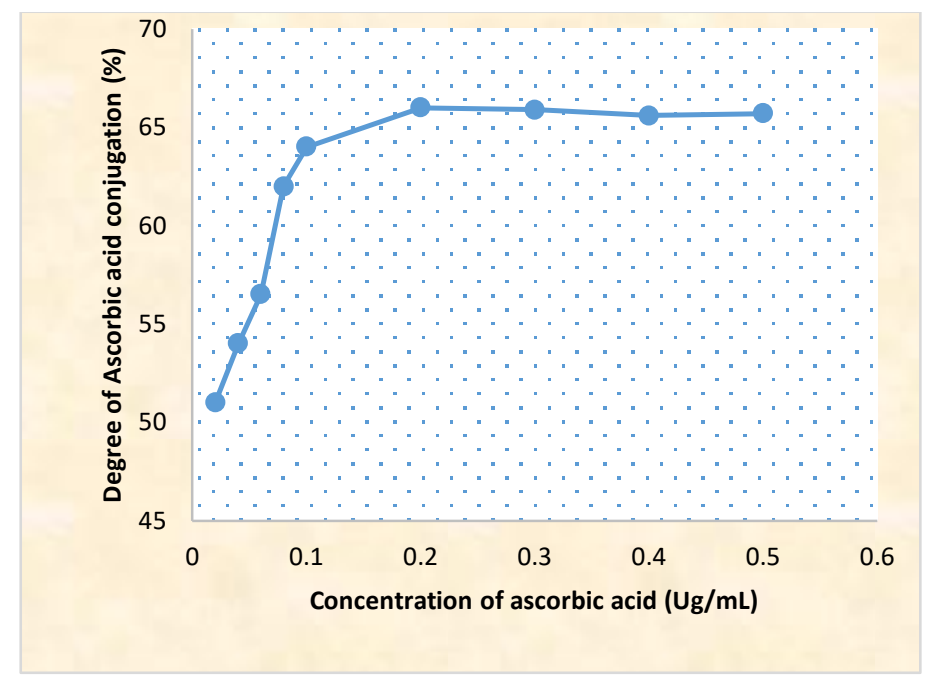

Figure 2: Degree of substitution on chitosan molecule by ascorbic acid

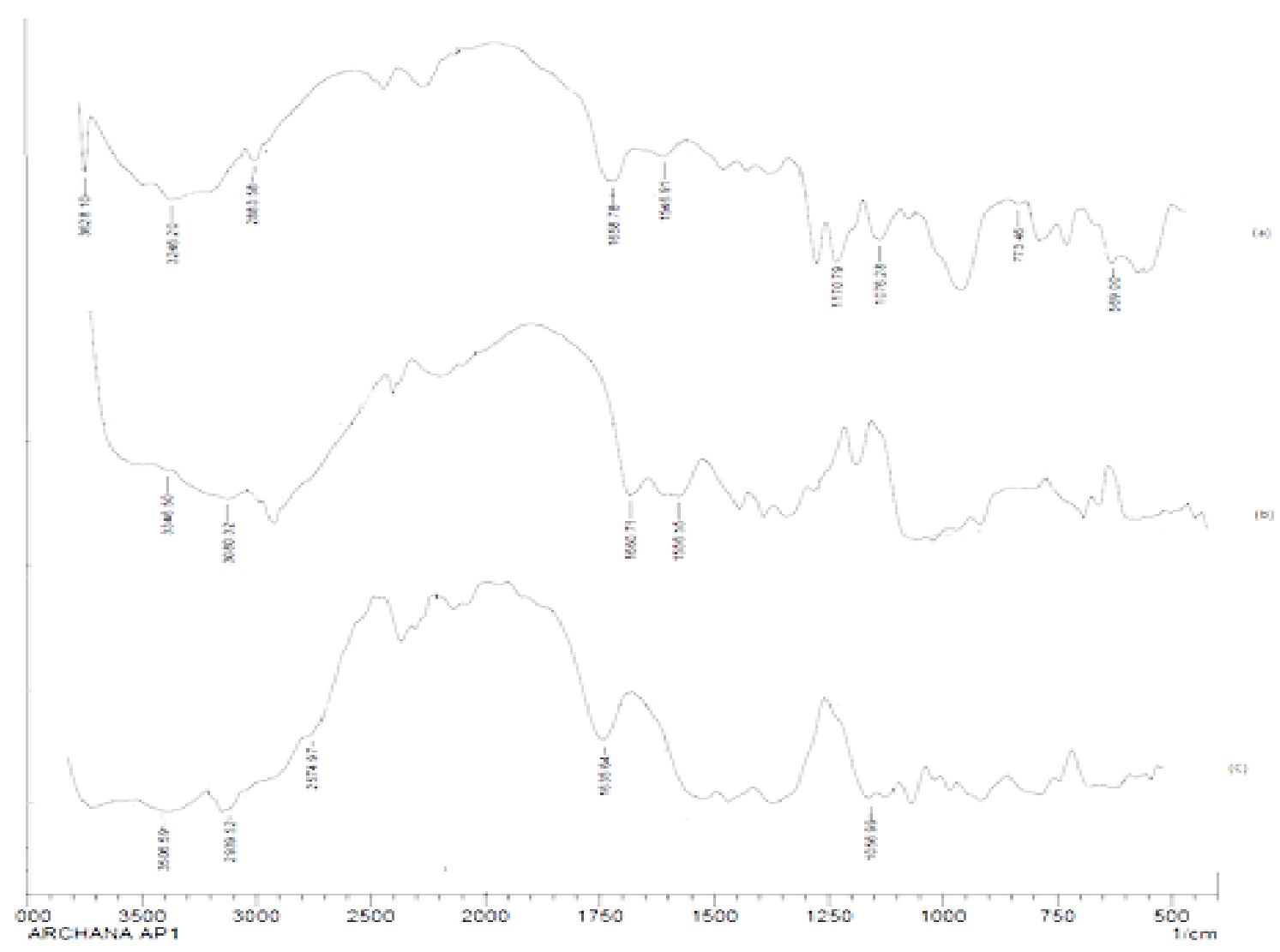

Figure 3: Comparative FTIR study of a). Chitosan, b). Ascorbic acid and c). After solubilisation

To characterize the mannosylation on CAMs system, in the mannose ligand, aside of the broad $\mathrm{O}-\mathrm{H}$ band in the $3391 \mathrm{~cm}^{-}$ 1 range, the minimum transmittance was in the 950$1200 \mathrm{~cm}^{-1}$ region where the $\mathrm{C}-\mathrm{O}-\mathrm{C}$ and $\mathrm{C}-\mathrm{O}-\mathrm{H}$ link band positions are found. The two shoulder peaks at 1064 and $1324 \mathrm{~cm}^{-1}$ can be attributed to the glycosidic links of mannose ${ }^{42}$. The characteristic wave numbers that can be used for the quantification of mannose, viz., 1157.5, 1294.8 and 916.2 were present in mannosylated chitosan ascorbate microspheres. FTIR studies on mannosylated chitosandisplayed decreasing intensities with peak broadening for various bands of chitosan as well as of mannose, implying an interaction between these chemical moieties. This clearly confirmed the presence of mannose on m-CAMs carrier system (Fig. 4). 


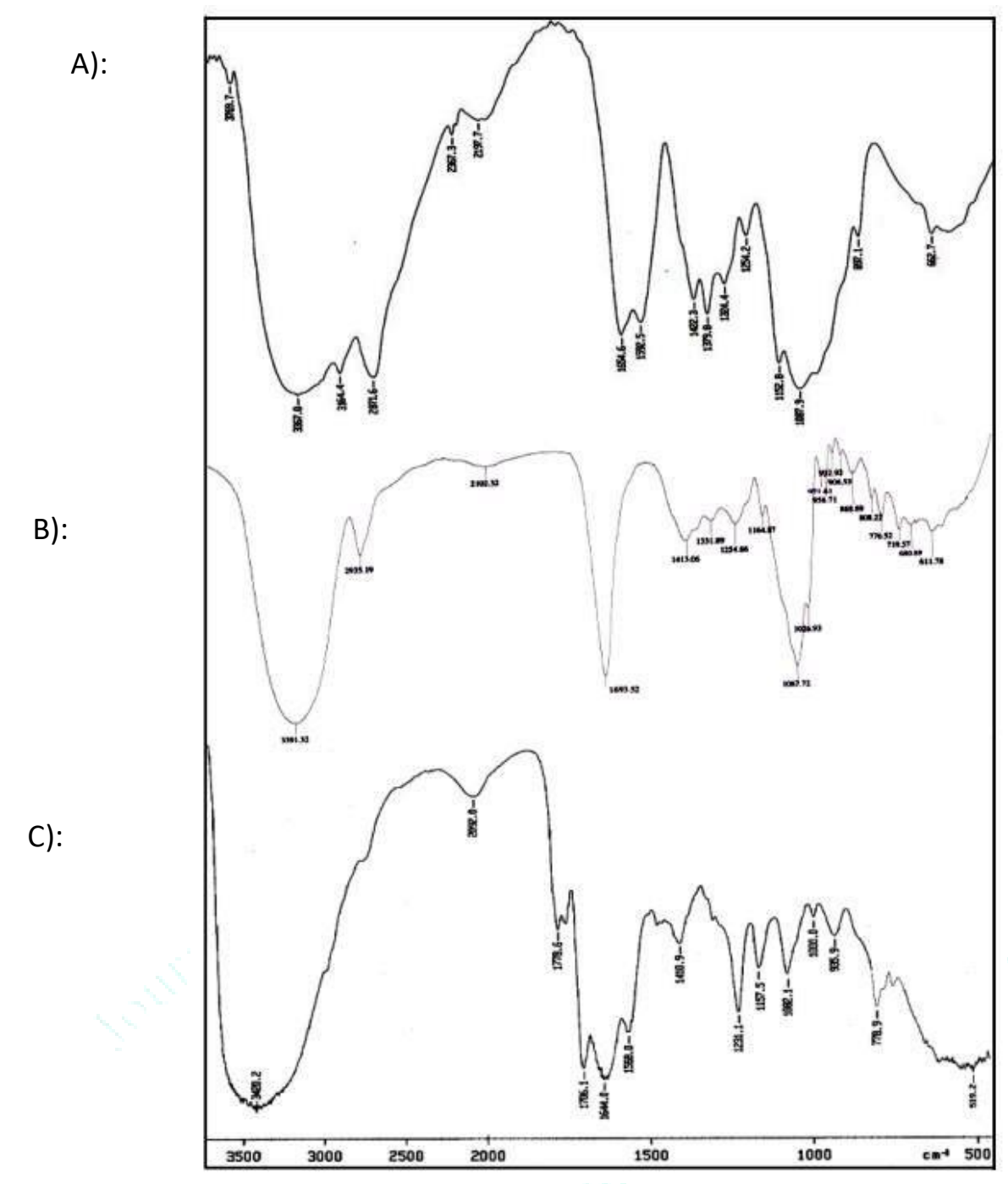

Figure 4: FTIR spectrum of (a) chitosan ascorbate microsphere (CAMs), (b) mannose ligand, (c) Mannosylated chitosan ascorbate (m-CAMs)

\section{Entrapment efficiency:}

The results confirmed the better entrapment efficiency of INH in both CAMs and m-CAMs. The possible reason may be the hydrophilicity of INH and being hydrophilic in nature polymeric matrix provided a safe home to hydrophilic INH. Further the lower drug entrapment in case of mannosylated carrier system as compare to plain, may possibly be due to the during mannosylation reaction that involves incubation in sodium acetate buffer ( $\mathrm{pH} \mathrm{4.0)}$ ) for period of $24 \mathrm{~h}$ which might have led to leaching of drug in reaction medium.
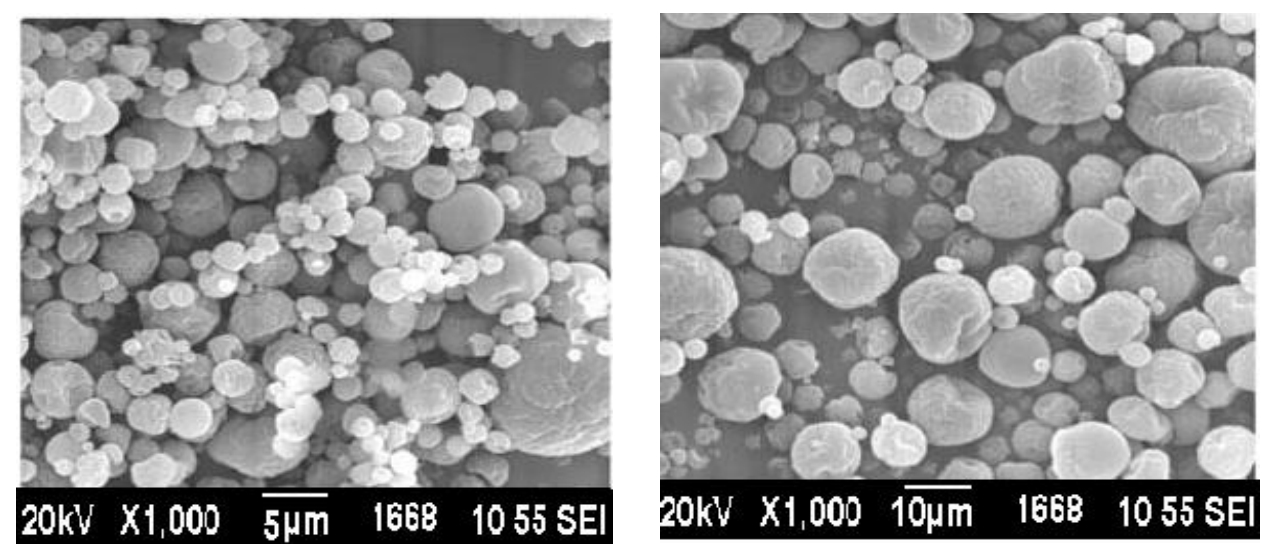

Figure 5: SEM image of a): chitosan microspheres (CAMs) b): mannosylated chitosan microspheres (m-CAMs) 
PXRD:

To determine the physical state of physical interaction of polymer and incorporation of drug to carrier system PXRD recorded of INH, blank CAMs, physical mixture of INH and CAMs, INH loaded CAMs and INH loaded m-CAMs and differactogram were shown in Fig. 6.

Diffraction spectrum of INH showed distinct and high intensity peaks in the region of $2 \theta$ ranging from $15^{\circ}$ to $25^{\circ}$. INH displays PXRD pattern with sharp and intense peaks, denoting a highly crystalline structure. The pattern matches that described in the literature 43 and no other peaks than those belonging to the INH crystalline phase were found. However, in case of INH-loaded CAMs, no such peaks could be observed. This could have occurred due to entrapment of drug within the microspheres. From these observations, we concluded that the drug was efficiently loaded within the microspheres and the amount of surface-adsorbed drug could be considered as negligible. The diffractograms of the INH loaded CAMs and m-CAMs for INH are shown the typical XRD peaks of both systems. When the drug was loaded into chitosan polymer in the form of microspheres the intensity of each peak markedly decreased. This is a sign of the drug(s) inclusion into both CAMs and m-CAMs formulations.

\section{In-vitro lung deposition study}

Removal of drug with delivery system and aerosolisation performance for carrier system was investigated using Andersen Cascade Impactor (ACI). The ACI is comprised of different plates or stages corresponding to the different regions of the respiratory system, from the oral cavity to alveoli. The particulate matter is drawn at a predetermined air-flow rate through the apparatus, resulting in deposition of the particles on different plates of ACI as a function of their particle size and aerodynamics.

The ACI is similar to a twin stage impinger (TSI) in function. However in addition to particle size, it gives a detailed lung deposition data with additional parameters like \%ED, MMAD and FPF. Mass Median Aerodynamic Diameter (MMAD) represents the average diameter below which $50 \%$ of the particles remain. The emitted dose (ED), i.e. the mass of drug deposited in the induction port, the stages and the filter, was expressed as the percentage (\%ED) of the total recovered mass (i.e. from the induction port, the stages and the filter from the adapter, the inhaler and capsule) whereas FPF is generally regarded as the fraction of the total inhaled dose that reaches the stages corresponding to the cut-off diameter of $5 \mu \mathrm{m}$.

The $\%$ ED values for all microspheres were high in the range from $85.1 \%$ to $89.6 \%$, and this corresponds to minimal retention in the capsule and indicating that the microsphere powder was efficiently emitted from the Inhaler 46 . MMAD value for microspheres were found (between 2-5 $\mu \mathrm{m}$ ) satisfactory for delivery to the alveoli where the mycobacterium infection is mainly present (Fig. 7).

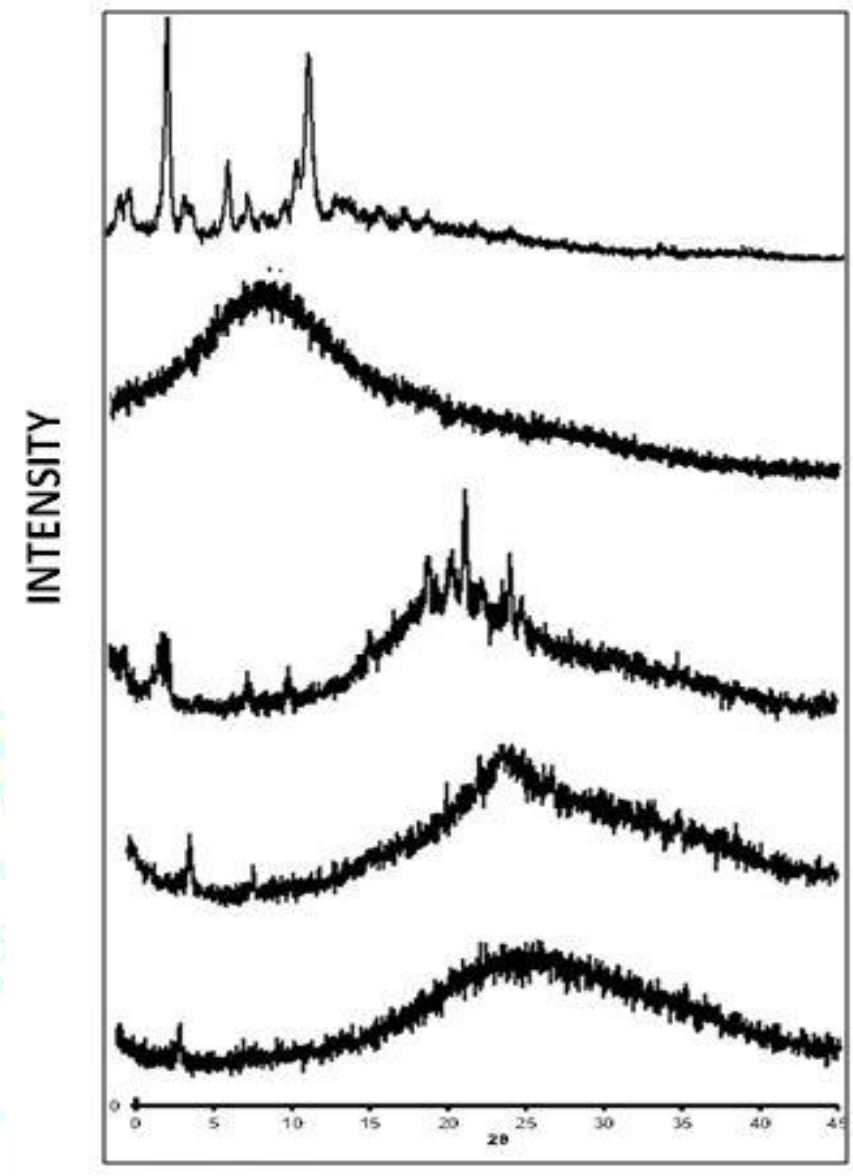

Figure 6: Comparative PXRD of INH and various formulations

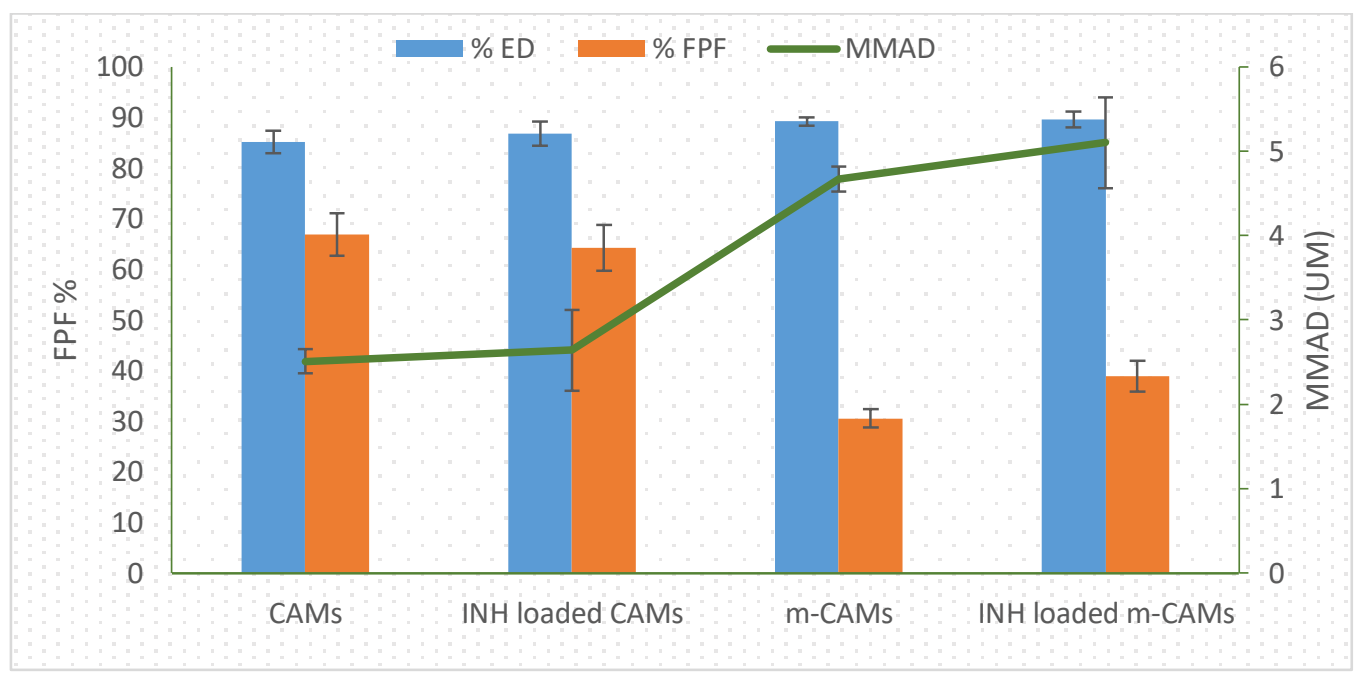

Figure 7: In-vitro lung deposition study 
The lower MMAD and high FPF found with formulation of mannosylated carrier system that shown prepared formulation compatible with dry powder for inhalation. The $\%$ FPF depicted that the larger dose was available to the lungs after inhalation hence it help to target the formulation towards alveolar macrophage cells where the tubercular bacilli reside.

\section{In-vitro drug release:}

The release studies were carried out in two different simulated lung fluids as release medium, which is used to evaluate human exposure to particulates from environmental emissions. ALF is analogous to the fluid with which inhaled particles would come into contact after phagocytosis by alveolar and interstitial macrophages in the lung. Gamble's solution represents the interstitial fluid deep within the lung.

Cumulative In-vitro release profile of INH loaded CAMs and $\mathrm{m}$-CAMs were presented in Fig. 8 ( $\mathrm{a}$ and b). At pH 7.4, INH loaded CAMs and m-CAMs formulations showed percent cumulative release of approximately $86 \%$ and $74 \%$ whereas at $\mathrm{pH} 4.5,80 \%$ for INH loaded CAMs and $78 \%$ for m-CAMs, at the end of $72 \mathrm{~h}$. The aqueous solubility of INH was high so the \% cumulative release of INH from chiotsan microsphere is high and at acidic $\mathrm{pH}$ the swelling of polymer takes place which could enhance the drug(s) mobility and diffusion. It can be concluded that the developed formulations were able to release the drug in sustained manner in the phagolysosomal bio milieu. The release pattern of drug from both microsphere formulations followed a biphasic pattern, characterized by an initial burst, followed by a slower sustained release. The initial burst release may be due to the release of the drug present at or just beneath the surface of microspheres. Thereafter the release occurred due to the polymer erosion and diffusion of the drug molecules. The diffusion of drug(s) is through small pores and channels in the polymer matrix. Hence our carrier system releases drug inside Alveolar macrophage at late phagosomal phase of phagocytosis in controlled manner by erosion mechanism which may help in reduction in dosing frequency of drug, so this delivery system will be able to retain high amount of drug in the acidic $\mathrm{pH}$ and would be able to release more drug in the alveolar macrophages at the desired site of drug 47,48 .

\section{In vitro cell proliferation study:}

The cytotoxic effects of INH against A549 cells were examined by MTT assay. In the experiments, the cytotoxicity was evaluated by varying the concentration of free INH solution, drug loaded CAMs and m-CAMs. Cytotoxicity was observed to be INH concentration-dependent for all the tested samples (Fig. 9). The highest cytotoxic effects were found for free INH, which even in the lowest concentration $(20 \mu \mathrm{l} / \mathrm{mL})$ showed only a $55 \%$ cell viability that further decreased to $20 \%$ when the free drug was used in the highest concentration $(100 \mu \mathrm{l} / \mathrm{mL})$. These results show the high toxicity of INH that can cause side effects also when it is nebulized directly into the lung, where is the site of infection. The viability assay also showed that INH toxicity can be reduced by entrapped the drug in chitosan microspheres. Cell viability was generally not affected by chitosan concentration, in fact empty particles showed always the best results in term of viability. As can be seen in Fig. 9, the presence of mannosylation slightly decreased the viability of cells probably may be because of STPP was in the microspheres also after the purification steps.
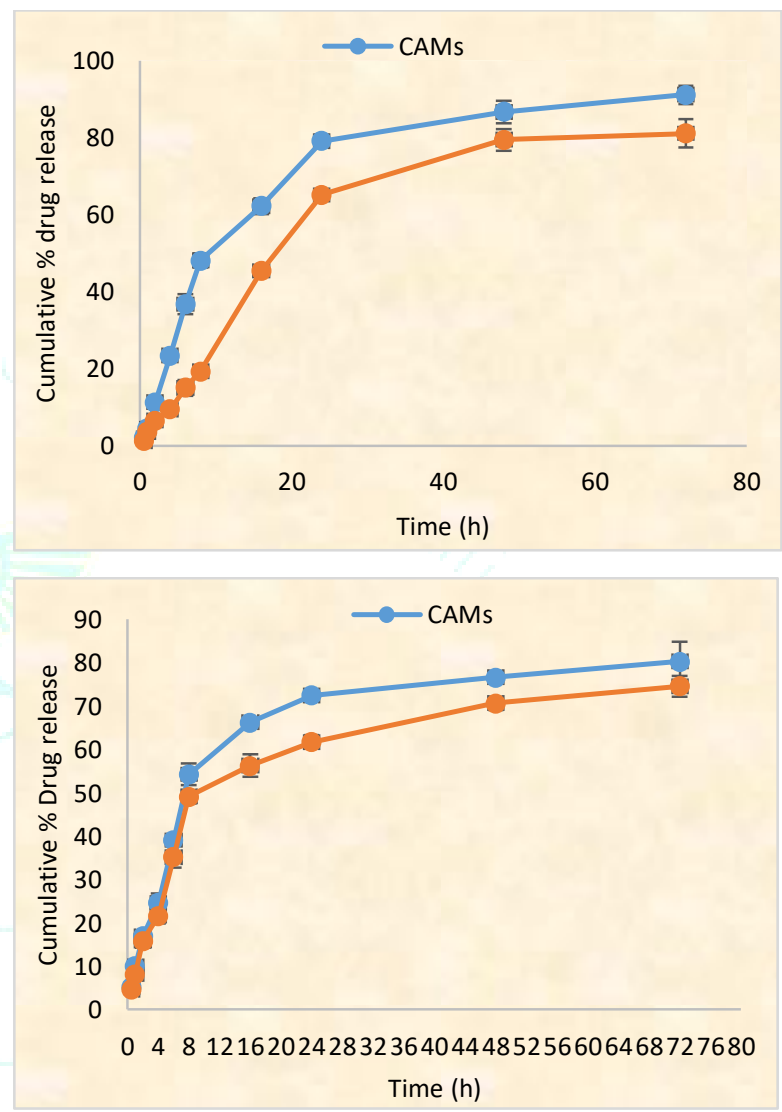

Figure 8: In-vitro Drug Release INH from formulation a): at $\mathrm{pH} 7.4$ and b): at $\mathrm{pH} 4.5$

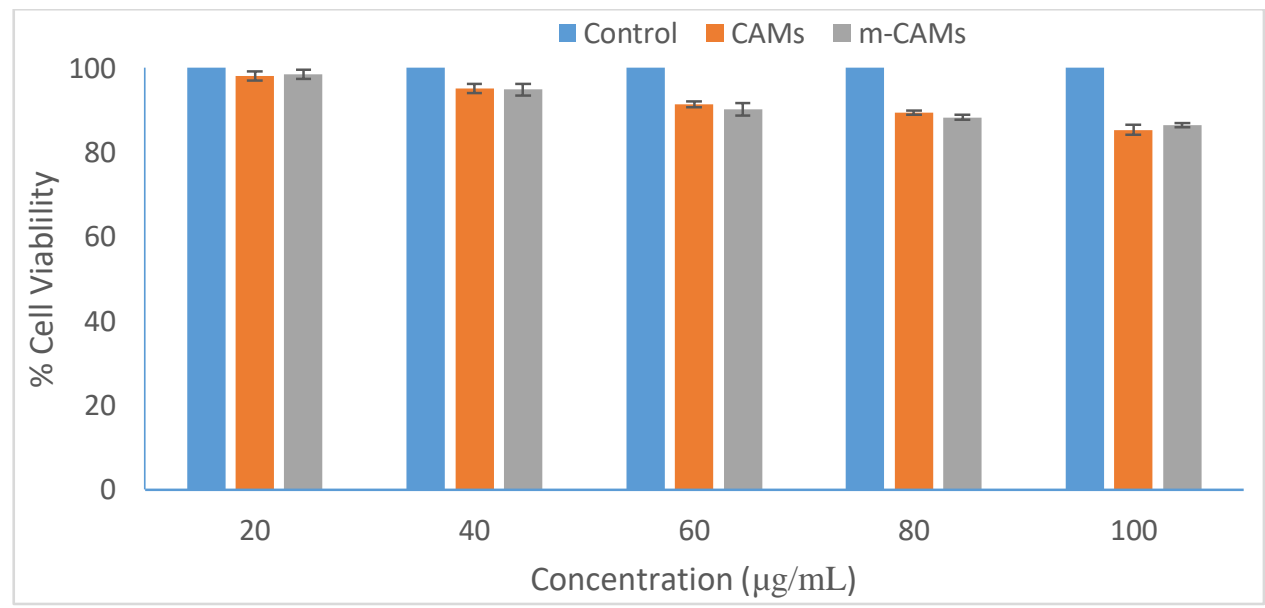

Figure 9: Effect of CAMs and m-CAMs for cell viability by MTT on A549 cell lines 


\section{Pharmacokinetics and Bio distribution:}

Various pharmacokinetic parameters such as Cmax $(\mu \mathrm{g} / \mathrm{ml})$, Tmax (h), and AUC 0-24 ( $\mu \mathrm{g} \mathrm{h} / \mathrm{ml})$ of the developed optimized microspheric formulation was determined and compared with the plain INH solution (Table: 6) and organ distribution of drug in various organs shown in Fig.10 (A-D). It was observed that peak plasma concentrations of the drug were achieved quickly in case of plain drug compared with the developed formulation. A significant higher Tmax and AUC in experimental formulation could be related to controlled and localized drug delivery under the physiological conditions. The higher values of AUC of developed formulations clearly indicated that drug concentrations were maintained within the pharmacologically effective range for longer period of time.

From in vivo studies, it was observed that there was a significant increase in drug accumulation within the desired cellular tropics when they were administered in microspheric form (CAMs and m-CAMs) formulations. As expected, the plasma and organ distribution studies had shown higher amount of drug(s) recovery from lungs in the case of both the ligand conjugated formulations as compared to plain counterparts and free drug, indicating the efficacy of developed carrier for lung targeting of INH.

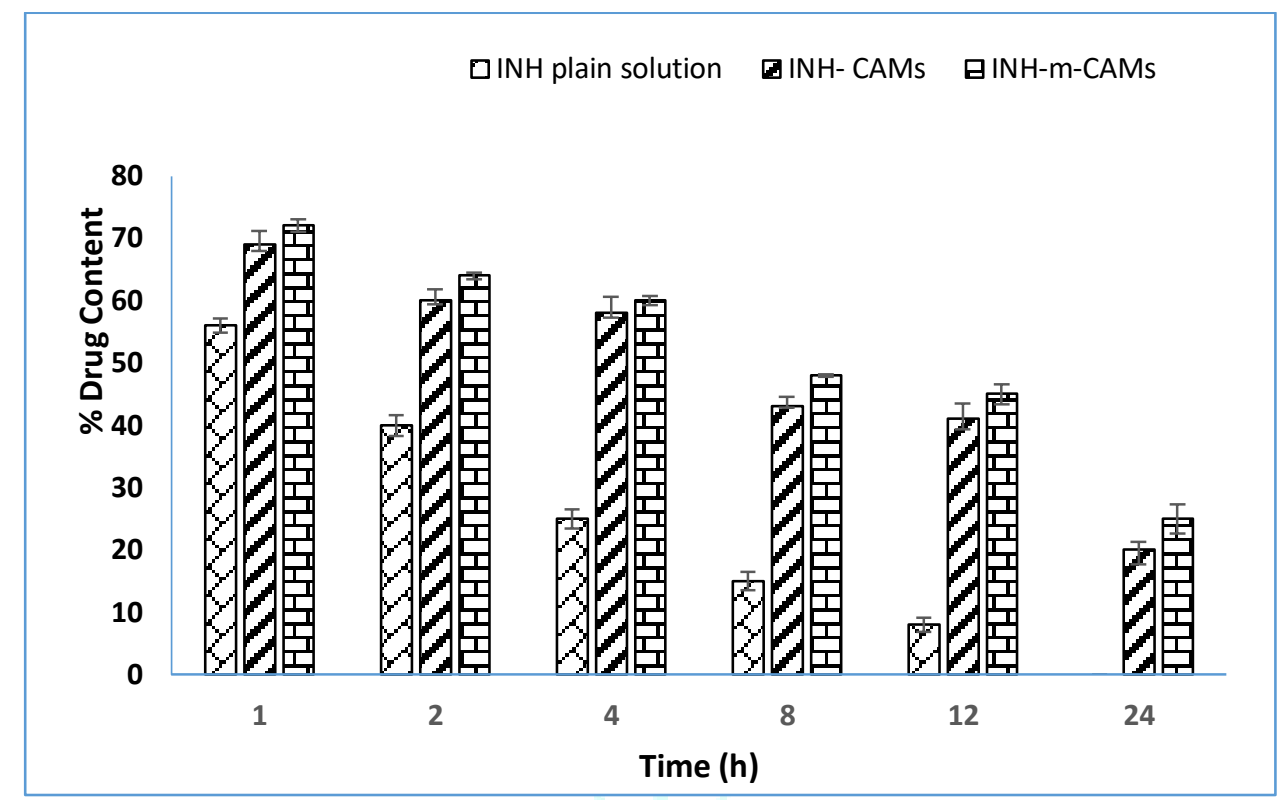

A): In lungs

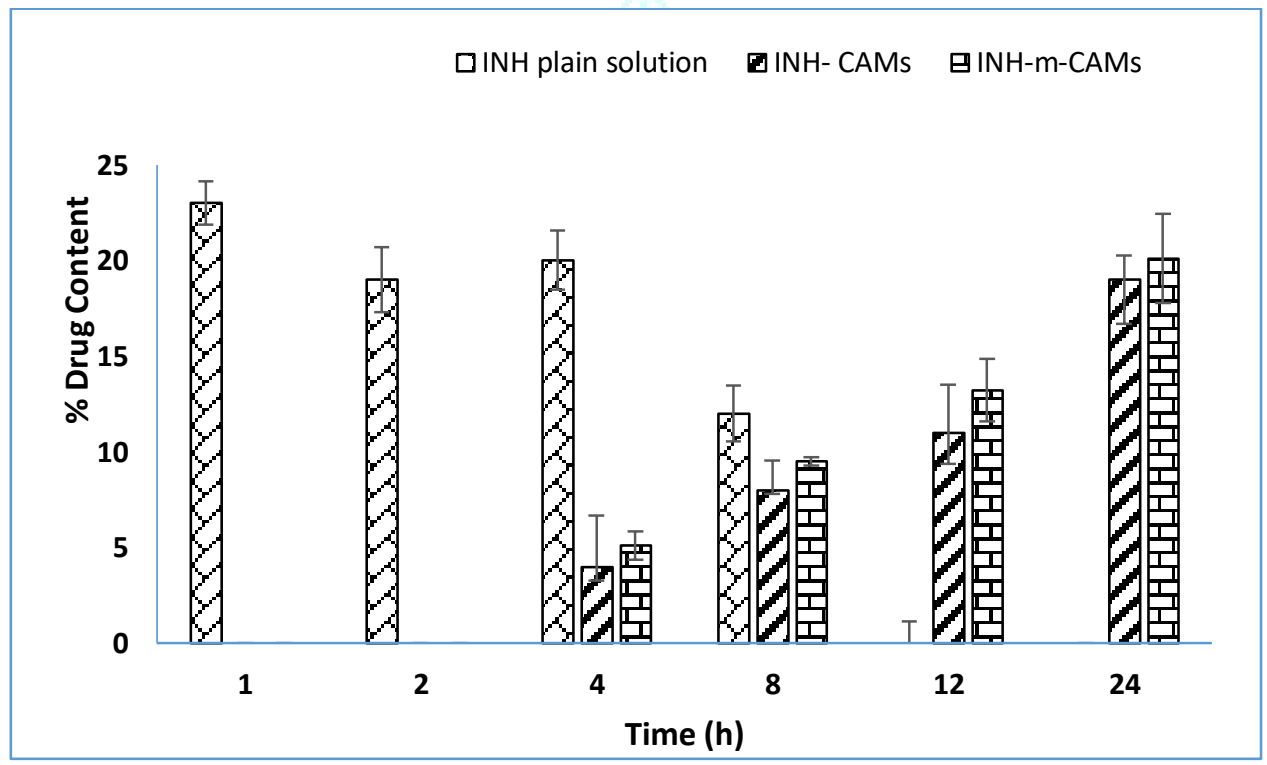

B): In liver

Figure 10(A): In vivo organ distribution of INH administered as CAMs loaded and $\mathbf{m}$-CAMs loaded as compare to plain solution (mean $\pm S D, n=3$ ). 


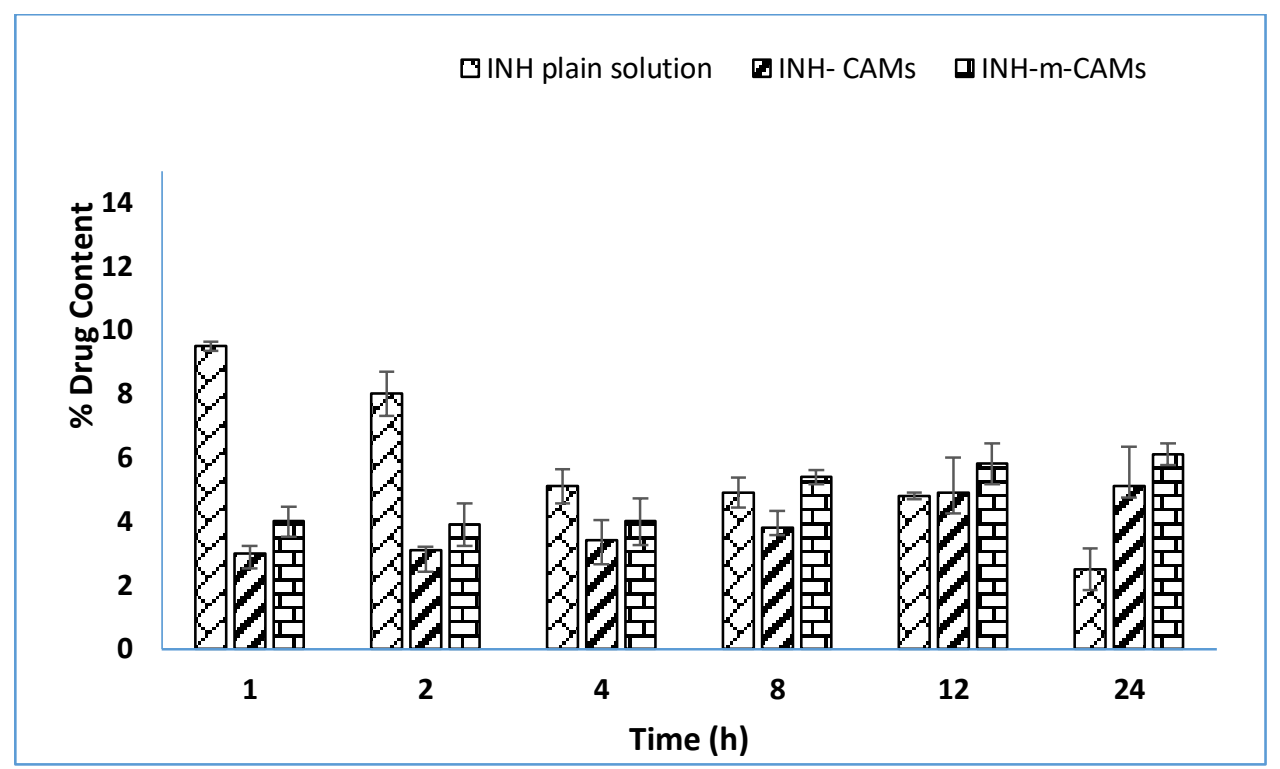

C): In spleen

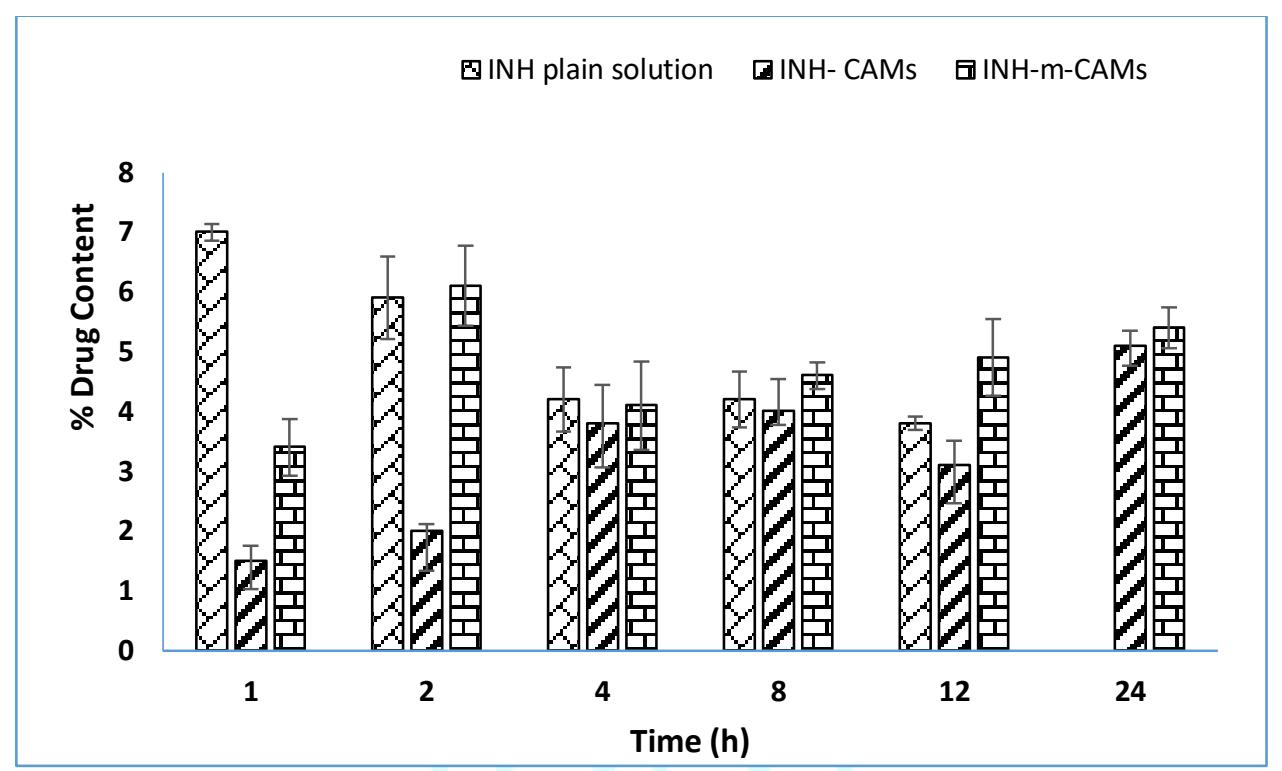

D): In kidney

Figure 10(B): In vivo organ distribution of INH administered as CAMs loaded and $\mathrm{m}$-CAMs loaded as compare to plain solution (mean $\pm S D, n=3$ ).

Table 6: Pharmacokinetic parameters after pulmonary administration of free drug solution and microspheric formulations into Balb/c mice.

\begin{tabular}{llll}
\hline Formulation & Cmax & Tmax & AUC $0-24 \mathrm{~h}(\mu \mathrm{g} / \mathrm{ml} / \mathrm{h})$ \\
\hline Free drug INH & $5.55 \pm 1.21$ & $2.03 \pm 0.74$ & $32.47 \pm 5.14$ \\
INH-CAMs & $8.81 \pm 0.14$ & $16.41 \pm 0.81$ & $309.1 \pm 7.10$ \\
INH-m-CAMs & $9.21 \pm 1.74$ & $19.48 \pm 0.44$ & $331.24 \pm 1.1$ \\
\hline
\end{tabular}

\section{CONCLUSION}

Inhalable chitosan ascorbate microsphere were successfully prepared by salification of chitosan with ascorbic acid and then fabricated by ionic gelation method, hence the captivative antioxidative potential and non-toxic nature of carrier system in which first line antitubercular drug (INH) incorporated for treatment of pulmonary tuberculosis. The microsphere then further mannosylated to m-CAMs, so targetability of isoniazid to alveolar macrophages increased. The microsphere did not affect the viability of A549 cells during in-vitro condition. Overall, results obtained from various studies so far indicate a potential application of the proposed systems in pulmonary tuberculosis therapy. Hence this approach for delivery of isoniazid loaded mannospylated chitosan microspheres to alveolar macrophages has been successfully attempted.

\section{ACKNOWLEDGEMENTS}

The authors would also like to express their gratitude to Ms. Lupin Ltd, Aurangabad (India) for providing gift sample of Isoniazid. The authors are also thankful to MSME 
Department, Maulana Azad National Institute of Technology, Bhopal, (India) for carrying out Scanning Electron Microscopy analysis. The authors would like to thank Gene Explore Diagnostic and Research Center for carrying out cell viability studies.

\section{DECLARATION OF INTEREST}

The authors declare no conflict of interest. This work was funded by Women scientist Fellowship (WOS-A) scheme, Department of Science and technology (DST), Government of India for providing financial aid for the project (Sanction order no. SR/LS-1086/WOS-A/2014, dated 12.09.2016).

\section{REFERENCES}

1. WHO. Global Tuberculosis Report 2018; 114.

2. Lienhardt $\mathrm{C}$, Lonnroth $\mathrm{K}$, Menzies $\mathrm{D}$, et al. Translational Research for Tuberculosis Elimination: Priorities, Challenges, and Actions. PLoS Med. 2016; 13(3):e1001965.

3. Vieira ACC, Chaves LL, Pinheiro S, et al. Mucoadhesive chitosan-coated solid lipid nanoparticles for better management of tuberculosis, Int J Pharm. 2018; 536(1):478485.

4. Cunha L, Costa A, Lourenço J, et al. Spray-dried fucoidan microparticles for pulmonary delivery of antitubercular drugs. J Microencapsul. 2018; 35(4):392-405.

5. Booysen LL Kalombo L, Brooks E, et al. In vivo/in vitro pharmacokinetic and pharmacodynamic study of spray-dried poly-(dl-lactic-co-glycolic) acid nanoparticles encapsulating rifampicin and isoniazid. Int J Pharm. 2013; 444:10-17.

6. Priemel PA, Wang Y, Bohr A, et al. Poly (ethylene carbonate)containing polylactic acid microparticles with rifampicin improve drug delivery to macrophages, J Pharm Pharmacol. 2018; 70(8):1009-1021.

7. Parikh R, Dalwadi S, Preparation and characterization of controlled release poly- $\varepsilon$-caprolactone microparticles of isoniazid for drug delivery through pulmonary route, Powder Technol. 2014; 264:158-165.

8. Maretti E, Rossi T, Bondi M, et al. Inhaled Solid Lipid Microparticles to target alveolar macrophages for tuberculosis. Int J Pharm. 2014; 462(1-2):74-82.

9. Esmaeili F, Hosseini-Nasr M, Rad-Malekshahi M, et al. Preparation and antibacterial activity evaluation of rifampicinloaded poly lactide-co-glycolide nanoparticles, Nanomedicine. 2007; 3(2):161-167

10. Luo J, Sun J, Luo X, et al. Low molecular weight chitosan based conjugates for efficient Rhein oral delivery: synthesis, characterization, and pharmacokinetics, Drug Develop and Indust Pharm. 2018, 45(1):96-104.

11. Kumari S, Annamareddy SHK, Abantia S, et al. Physicochemical properties and characterization of chitosansynthesized from fish scales, crab and shrimp shells. Int. J Biol Macromol. 2017; 104:1697-1705.

12. Hafsa J, Charfeddine M, Smach $K$ et al. Synthesis, characterization, antioxidant and antibacterial proprieties of chitosan ascorbate, Int J Pharm Chem Biol Sci. 2014; 4(4):1072-1081.

13. Lee SB, Lee YK, Kim SD. Solubility, Antioxidative and Antimicrobial Activity of Chitosan-Ascorbate. J Korean Soc Food Sci Nutr. 2006; 35:973.

14. Rossi S, Vigani B, Puccio A, et al. Chitosan Ascorbate Nanoparticles for the Vaginal Delivery of Antibiotic Drugs in Atrophic Vaginitis. Mar Drugs. 2017; 15:319.

15. Vilcheze C, Hartman T, Weinrick B, et al. Mycobacterium tuberculosis is extraordinarily sensitive to killing by a vitamin C-induced Fenton reaction. Nature Communic. 2013; 4:18811889.

16. Vilcheze C, John Kim J, William R. et al. Vitamin C potentiates the killing of Mycobacterium tuberculosis by the first-2 line tuberculosis drugs isoniazid and rifampicin in mice. Antimicrob Agents Chemother. 2018; 62(3):e02165-17

17. Sekar V, Rajendran K, Vallinayagam S, et al. Synthesis and characterization of chitosan ascorbate nanoparticles for therapeutic inhibition for cervical cancer and their in silico modelling. J Ind Eng Chem. 2018; 62:239-249.
18. Mitchell JP, Roberts DR, Langley J, et al. A direct method for the formation of peptide and carbohydrate dendrimers. Bio Med Chem Let. 1998; 9:2785-2788.

19. Jayasree A, Sasidharan S, Koyakutty M, et al. Mannosylated chitosan-zinc sulphide nanocrystals as fluorescent bioprobes for targeted cancer imaging. Carbohydr Poly. 2011; 85:37-43.

20. Zhang J, Tan W, Wang G, et al. Synthesis, characterization, and the antioxidant activity of $\mathrm{N}, \mathrm{N}, \mathrm{N}$-trimethyl chitosan salts. Int J Biol Macromol. 2018; 118:9-14.

21. Chauhan K, Sharma R, Dharela $R$, et al. Chitosan-thiomer Stabilized Silver Nano-composites for Antimicrobial and Antioxidant Applications. RSC Adv. 2016; 6(79):75453-75464.

22. Colombo H, Lasco TM, Allen SS, et al. Recombinant guinea pig tumor necrosis factor alpha stimulates the expression of interleukin-12 and the inhibition of Mycobacterium tuberculosis growth in macrophages. Infect Immun. 2005; 73, 1367-1376.

23. Marques MR, Loebenberg R, Almukainzi M. Simulated biological fluids with possible application in dissolution testing. Disso Tech. 2011; 18(3):15-28.

24. Tiwari S, Chaturvedi AP, Tripathi YB, et al. Microspheres based on mannosylated lysine-co-sodium alginate for macrophagespecific delivery of isoniazid. Carbohy Poly. 2012; 87:15751582.

25. Jyoti K, Pandey RS, Kush $\mathrm{P}$, et al. Inhalable bioresponsive chitosan microspheres of doxorubicin andsoluble curcumin augmented drug delivery in lung cancer cells. Int J Bio Macro. 2017; 98:50-58.

26. Mosmann T. Rapid colorimetric assay for cellular growth and survival: application to proliferation and cytotoxicity assays. J Immunol Methods. 1983; 65:55-63.

27. Jayaram R, Shandil RK, Gaonkar $S$, et al. Isoniazid pharmacokinetics-pharmacodynamics in an aerosol infection model of tuberculosis. Antimicrob Agents Chemother. 2004; 48(8):2951-7.

28. Bhatt NB, Barau C, Amin A, et al. Pharmacokinetics of rifampin and isoniazid in tuberculosis-HIV-coinfected patients receiving nevirapine or efavirenz based antiretroviral treatment. Antimicrob Agents Chemother. 2014; 58:3182-3190.

29. Tian G, Longest PW, Li X, et al. Targeting aerosol deposition to and within the lung airways using excipient enhanced growth. J Aerosol Med Pulm Drug Deliv. 2013; 26:248-265.

30. Hafsa J, Charfeddine M, Smach $K$ et al. Synthesis, characterization, antioxidant and antibacterial proprieties of chitosan ascorbate, Int J Pharm Chem Biol Sci. 2014; 4(4):1072-1081.

31. Noor NM, Sheikh K, Somavarapu S. Preparation and Characterization of Dutasteride-loaded Nanostructured Lipid Carriers coated with Stearic Acid-Chitosan Oligomer for Topical Delivery. Eur J Pharm Biopharm. 2017; 117:372-384.

32. Curotto E, Aros F. Quantitative determination of chitosan and the percentage of free amino group. Analy Bio. 2011; 211:240241.

33. Jadidi-Niaragh F, Atyabi F, Rastegari A, et al. CD73 specific siRNA loaded chitosan lactate nanoparticles potentiate the antitumor effect of a dendritic cell vaccine in $4 \mathrm{~T} 1$ breast cancer bearing mice. J Cont Rel.2017; 246:46.

34. Sawtarie N, Cai Y, Lapitsky Y. Preparation of Chitosan/Tripolyphosphate Nanoparticles with HighlyTunable Size and Low Polydispersity. Colloids Surf B: Bioint. 2017; 5:055.

35. Pai RV, Jain RR, Bannalikar AS, et al. Development and Evaluation of Chitosan Microparticles Based Dry Powder Inhalation Formulations of Rifampicin and Rifabutin, J Aero Med Pulmon Drug Del. 2015: 28.

36. Singhavi DJ, Pundkar S, Khan S. Famotidine microspheres reconstituted with floating in situ gel for stomach-specific delivery: Preparation and characterization. J Drug Del Sc Tech. 2017; 41:251-259.

37. Li J, Huang Q. Rheological properties of chitosantripolyphosphate complexes: From suspensions to microgels. Carbohydr. Polym. 2012, 87, 1670-1677.

38. Tsai ML, Bai SW, Chen RH. Cavitation effects versus stretch effects resulted in different size and polydispersity of ionotropic gelation chitosan-sodium tripolyphosphate nanoparticle, Carbohydr. Polym. 2008; 71:448-457. 
39. Li J, Huang Q. Rheological properties of chitosantripolyphosphate complexes: From suspensions to microgels. Carbohydr. Polym. 2012; 87:1670-1677.

40. Lawrie G, Keen I, Drew B, Chandler-Temple A, Rintoul L, Fredericks P, Grøndahl L, Biomacromolecules 2007; 8:2533.

41. Gao YF, Liu WH, Li ZG, Ma CN. Assignment of infrared spectrum of L-ascorbic acid. Chin J Spectrosc Lab. 2002; 19:354-8.

42. Coimbra MA, Barros AS, Coelho E, et al. Quantification of polymeric mannose in wine extracts by FT-IR spectroscopy and OSC-PLS1 regression. Carbohydr polymer. 2005; 61:434440.

43. Chan JGY, Chan HK, Prestidge CA, et al. A novel dry powder inhalable formulation incorporating three first-line antitubercular antibiotics. 2013; Eur J Pharm Biopharm. 2013; 83:285-292.

44. Sarwar A, Katas H, Samsudin SN, et al. Regioselective Sequential Modification of Chitosan via Azide-Alkyne Click Reaction: Synthesis, Characterization, and Antimicrobial
Activity of Chitosan Derivatives and Nanoparticles. PLOS ONE. 2015; $10(4): e 0123084$.

45. Kucinska-Lipka J, Gubanska I, Strankowski M, et al. Synthesis and characterization of cycloaliphatic hydrophilic polyurethanes, modified with L-ascorbic acid, as materials for soft tissue regeneration. Mater. Sci. Eng. C. 2017; 75:671-681.

46. Lee HJ, Kang JH, Lee HG, et al. Preparation and physicochemical characterization of spray-dried and jet-milled microparticles containing bosentan hydrate for dry powder inhalation aerosols. Drug Design, Develop and Therapy. 2016; 10:40174030.

47. Prabhakar RA, Murugan A, Munusamy MA et al. Targeted delivery of rifampicin to tuberculosis-infected macrophages: design, in-vitro, and in-vivo performance of rifampicin-loaded poly (ester amide)s nanocarriers, Int J Pharm. 2016; 513(12):628-635.

48. Coowanitwong I, Arya V, Kulvanich P, et al. Slow release formulations of inhaled rifampin. The AAPS journal. 2008; 10(2):342-348. 